analysis also showed that the $E S R 2_{\mathrm{GGG}}$ haplotype significantly associated with a reduced chance of having poor response to anti-TNF drugs $(p=0.0009)$. Finally, a ROC curve analysis confirmed that a model built with 8 steroid hormone-related variants significantly improved the ability to predict drug response compared with the reference model including demographic and clinical variables ( $A \cup C=0.633$ vs. $\left.0.556 ; P_{\text {LRtest }}=1.52 \cdot 10-6\right)$.

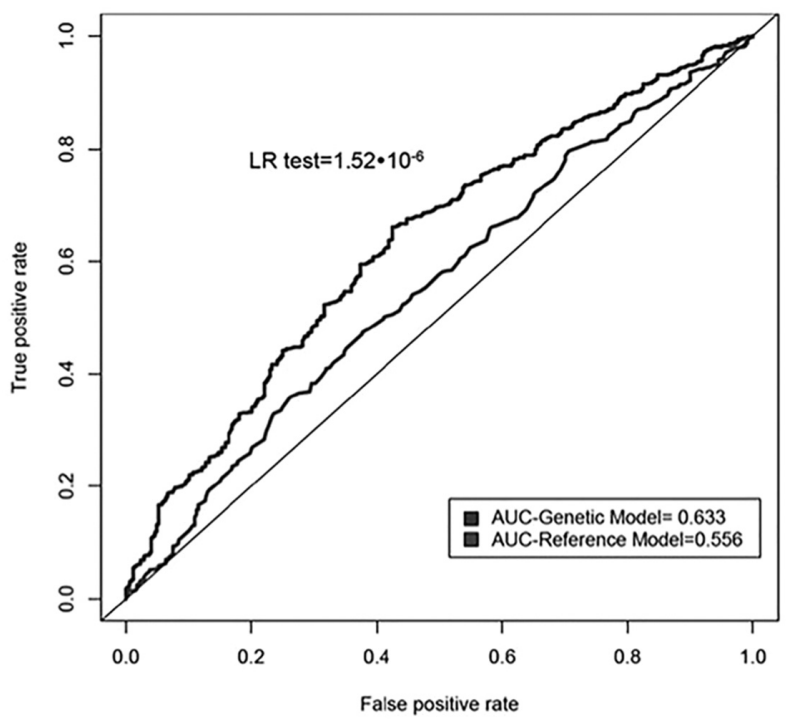

Conclusions: These data suggest that steroid hormone-related genes play a role in determining the response to anti-TNF drugs.

Disclosure of Interest: L. Canet: None declared, J. Sánchez-Maldonado: None declared, A. Rodríguez-Ramos: None declared, C. Lupiañez: None declared, H. Canhão: None declared, M. Martínez-Bueno: None declared, A. Escudero: None declared, J. Segura-Catena: None declared, S. Sørensen: None declared, M. Hetland: None declared, M. Soto-Pino: None declared, M. Ferrer: None declared, A. García: None declared, B. Glintborg: None declared, I. Filipescu: None declared, E. Pérez-Pampin: None declared, A. González-Utrilla: None declared, M. LópezNevot: None declared, P. Conesa-Zamora: None declared, A. den Broeder: None declared, S. da Vita: None declared, S. Hove Jacobsen: None declared, E. Collantes: None declared, L. Quartuccio: None declared, J. Fonseca: None declared, M. Coenen: None declared, V. Andersen Consultant for: VA has received compensation for consultancy and for being a member of an advisory board from MSD (Merck) and Janssen, R. Cáliz-Cáliz: None declared, J. Sainz: None declared DOI: 10.1136/annrheumdis-2018-eular.1108

\begin{tabular}{|l|l}
\hline THU0011 & LOCATION AND INTERACTION OF IGG \\
& HYPERVARIABLE REGIONS WITH PORPHYROMONAS \\
& GINGIVALIS PEPTIDYLARGININE DEIMINASE \\
& CITRULLINATED PEPTIDES, A HIGHLIGHT TO \\
& UNDERSTAND THE ASSOCIATION MODEL OF \\
& RHEUMATOID ARTHRITIS AND PERIODONTAL \\
& DISEASE: IN SILICO ANALYSIS
\end{tabular}

M. Acevedo-Godoy ${ }^{1}$, P. Hernandez ${ }^{2}$, A. Amaya ${ }^{1}$, D.M. Castillo ${ }^{1}$, J.E. Castellanos ${ }^{2}$ J.M. Bello-Gualtero ${ }^{3,4}$, W. Bautista-Molano ${ }^{1,4}$, C. Romero-Sanchez ${ }^{1,3,4}$. ${ }^{1}$ Unit of Oral Basic Investigation - UIBO; ${ }^{2}$ Vice-rectory for Research, Universidad EI Bosque; ${ }^{3}$ Rheumatology and Immunology, Hospital Militar Central; ${ }^{4}$ Clinical Immunology Group, Universidad Militar Nueva Granada, Bogotá D.C., Colombia

Background: $\lg$ antibodies against citrullinated peptides are one of the most specific biomarkers used in the classification of the disease. The relationship between RA and periodontal disease is based on the process of citrullination. The enzyme in the most important bacteria related with periodontitis (Porphyromonas gingivalis) the Peptidylarginine Deiminase (PPAD) modify arginine residues to citrulline

Objectives: To model in silico the binding of PPAD peptides with the hypervariable regions of $\lg G$
Methods: One PPAD peptide with 15 residues was selected in silico by its recognition by B cells (Bcepred y ABCpred) and T lymphocytes (ProPred, MHCPred). The peptide arginines were changed in silico by citrulline (Cit) with the ACD/ ChemSketch software, obtaining four different peptides, natural, Arg1 changed, Arg1-Arg8 changed and a random sequence. The 3D peptide modelling was obtained using PEP-FOLD Server and the 3D structure of variable domains of the heavy and light chain of IgG was obtained with the SwissModel. The amino acids of the hypervariable regions capable of interacting were defined using ConSurf Server. The peptides and variable domains were prepared using Openbabel. Docking models were performed by Patchdock and PyMOL tool was used to ren dering the structural complexes obtained

Results: The 3D structure of IgG variable domains had a QMEN6 z-score $<1$ Modelling of the topological disposition of the amino acids was obtained and the interaction scores between the four peptides and light and heavy chain hypervariable regions were high, although the better score was in the natural peptide and light chain interaction. The heavy chain showed also a high score during the in silico interaction with the Cit1-Cit8 modified peptide. The approximate interface area of the receptor-ligand complex and the contact atomic energy (ACE) between the ligand and the receptor revealed the energy required for the interaction allowing its stability. The PPAD-lgG complexes showed the atomic contact maps in which the heavy chain hypervariable region contacted seven amino acids in all four peptides while only six contacts occurred between light chain and the peptides. The model showed the interactions between light chain and natural peptide (Arg1 with Gly100, Arg8 with Glu1) and for Cit1-Cit8 peptide, Cit8 interact with Thr10 (Cit1 has no contact). Regarding the heavy chain, Arg1 of natural peptide interacted with Trp47 while for Cit1-Cit8 peptide were Cit1 with Lys43 and Cit8 with Pro40

Conclusions: The in silico model shows bacterial PPAD peptides with and without citrullination interact with the hypervariable regions of human IgG. The citrulline residues modify the 3D structure influencing the contact area with the heavy and light chain variable regions. Peptide with modifications of two arginine residues by citrulline presented a high interaction score indicating that may have an effective recognition for IgG

Disclosure of Interest: None declared

DOI: 10.1136/annrheumdis-2018-eular.3171

\section{THU0012 TARGETED RE-SEQUENCING OF 128 RHEUMATOID ARTHRITIS SUSCEPTIBILITY GENES UNCOVERS NOVEL RISK LOCI IN THE SINGAPORE CHINESE POPULATION}

J.M.Y. Yong ${ }^{1}$, L.L. Goh ${ }^{1}$, C.W. Lim ${ }^{1}$, P.P.Q. Lim ${ }^{1}$, G. L.-X. Toh ${ }^{1}$, E.T. Koh ${ }^{2}$, K. P. Leong ${ }^{2}$, the TTSH RA Study Group ${ }^{2} .{ }^{1}$ Clinical Research and Innovation Office; ${ }^{2}$ Rheumatology, Allergy and Immunology, Tan Tock Seng Hospital, Singapore, Singapore

Background: Rheumatoid arthritis (RA) is a fairly common inflammatory autoimmune disease with a prevalence of $1 \%$ to $1.5 \%$. Patients experience chroic joint pain, swelling and overtime irreversible joint damage. Genetic variants known to contribute to rheumatoid arthritis (RA) susceptibility have been reported in more than 120 genes, including the HLA, PTPN22, CTLA4, TNFAIP3, PADI4, FCRL3, CD4, CD244 and CD40. The genetic susceptibility to RA has not been studied in the Singapore population.

Objectives: To identify novel risk variants in candidate genes previousy reported to be associated with rheumatoid arthritis (RA) in Singapore Chinese RA patients positive for anti-citrullinated peptide antibodies (ACPA).

Methods: All the 128 known candidate genes associated with RA identified through GWAS were sequenced in 48 RA patients and 45 controls. The resultant data was analysed for association using single variant association and pathwaybased association enrichment tests. In addition, the genetic burden due to rare variants was assessed using the $\mathrm{C}$-alpha test. The candidate variants that showed significant association were validated in a larger cohort of 500 RA cases and 500 controls using mass array and Taqman technologies.

Results: 39 variants in 18 genes were identified using single variant association analysis and C-alpha test. IL6ST, with stepwise filtering. Among these, the missense variant in IL6ST, 5:55260065 (p.Cys47Phe) was significantly associated with RA in the Singapore Chinese patients $(\mathrm{p}=0.0194)$. The insignificant results of additional potential rare variants such as IL6ST, 5:55237103 and PXK rs199881366 is highly due to the limitations of our small sample size.

Conclusions: Our results suggest that IL6ST, 5:55260065, 5:55237103 and PXK rs 199881366 confer risk of RA in ACPA-positive Chinese patients.

Disclosure of Interest: None declared

DOI: 10.1136/annrheumdis-2018-eular.1182 